\title{
Sensitivities of various Oomycetes to hymexazol and metalaxyl
}

\author{
Shigehiro Kato,${ }^{1} \uparrow$ Richard Coe, ${ }^{2}$ Laura New ${ }^{2}$ and Michael W. Dick ${ }^{1 *}$ \\ ${ }^{1}$ Department of Botany, University of Reading, 2 Earley Gate, Whiteknights Road, PO Box 239, Reading RG6 2AU, UK \\ ${ }^{2}$ Department of Applied Statistics, University of Reading, Blandford Lodge, Whiteknights, PO Box 217, \\ Reading RG6 $2 A N$, UK
}

(Received 27 March 1990; revised 29 May 1990; accepted 22 June 1990)

\begin{abstract}
The effect of hymexazol on the linear extension of hyphae of a range of Oomycetes was examined. Twenty-five species were compared using four fungicide concentrations. Cluster analysis was used to look for similarities between species. The response of each taxon to the different concentrations of hymexazol was modelled. The parameters of these curves were then subjected to multivariate analysis. Both analyses revealed close relationships between the sensitivity to the fungicide and the current classification of the Oomycetes. Comparisons were made with the effect of metalaxyl on the same isolates.
\end{abstract}

\section{Introduction}

Hymexazol has been used widely for the control of damping-off of rice, sugar beet and some other crops caused by Pythium (Peronosporomycetidae), Aphanomyces (Saprolegniomycetidae) and some other soil-borne pathogens (Takahi et al., 1974). The fungicide is also used commonly in selective media for isolation of Phytophthora (Peronosporomycetidae) species from soil and plant tissues, because it was reported to inhibit selectively most species of Pythium and Mortierella (Zygomycotina) but not Phytophthora species (Masago et al., 1977). However, Ho (1987) demonstrated that hymexazol strongly inhibited growth and reproduction of some species of Phytophthora.

The differential responses of species within particular genera have not been subjected to comparative assessment. Pythium contains saprophytic, facultatively parasitic, obligately plant pathogenic, and mycopathogenic taxa, and so any differential sensitivity following hymexazol application will affect community structure in vivo. Assessment of community composition by selective methods of isolation would also require qualification. This paper outlines the probable diversity of responses to fungicides that may be displayed by the Oomycetes as a class and attempts to establish whether different taxonomic groups within the Oomycetes show distinctive behaviour. For this study a wide range of

\footnotetext{
† Present address: Sankyo Co., Agricultural Chemicals Research Laboratories, Shiga, Japan.
}

concentrations of fungicides was necessary, and the single parameter of $\mathrm{LD}_{90}$ was inadequate to characterize differences. Stress is therefore placed on differences in the shapes of the inhibition curves.

\section{Methods}

Species

Saprolegniomycetidae

Leptomitales. Apodachlya brachynema (Hildebrand) N. Pringsh. (APCC 5001a, N.W. England, 1963†); Leptomitus lacteus (Roth) Agardh (APCC 5005a, N. W. England, 1962†).

Saprolegniales. Aphanomyces laevis de Bary (APCC 3003a* from CBS 107.52, ?USA, prior to 1952); Aplanopsis spinosa Dick (APCC 3101f, Reading Campus, UK, 1988†), Aplanopsis terrestris Höhnk (APCC 3102e, Reading Campus, UK 1988†); Isoachlya eccentrica Coker (APCC 2501d, from CBS 211.35 to IMI 308223, ?England, 1935); Leptolegnia caudata de Bary [APCC 3501d, Naini Tal, India (received as ?L. eccentrica), 1980]; Saprolegnia furcata Maurizio (APCC 2005b to CBS 543.67, Reading Campus, UK, 1967†); Thraustotheca clavata (de Bary) Humphrey (APCC 3701a to IMI 308200, N.W. England, 1962†).

Sclerosporales. Pachymetra chaunorhiza Croft \& Dick (APCC 8500a, from CBS 672.85 to IMI 324448, N. Queensland, Australia, 1985, type culture), Verrucalvus flavofaciens Wong \& Dick (APCC 6001a*, NSW, Australia, 1975, type culture).

Rhipidiomycetidae

Sapromyces elongatus (Cornu) Thaxter (APCC 5101a, ?USA, ?date).

Peronosporomycetidae

Pythiales. Pythium aquatile Höhnk (APCC 4106a*, Reading Campus, UK, 1973†), Pythium aphanidermatum (Edson) Fitzpatrick (APCC 4104b* from IMI 280185, Japan, 1981), P. intermedium de Bary 
(APCC 4309e*, from CBS 221.68 to IMI 308149, The Netherlands, 1968), Pythium paddicum Hirane (APCC $4322 \mathrm{a}^{*}$ from IMI 280172 , Japan, 1982), Pythium rostratum Butler (APCC 4329b* to IMI 308314, Reading Campus, UK, 1973†), Pythium torulosum Coker \& Patterson (APCC 4212a to IMI 308265, N.W. England, 1964†), Pythium vexans de Bary (APCC 4017a* to IMI 308244, Reading Campus, UK, 1973†), Pythium HS group (APCC $4309: 204^{*}$, Reading Campus, UK, 1980†); Phytophthora cactorum (Lebert \& Cohn) Schroeter (APCC $4505 \mathrm{~d}^{*}$ from IMI 129909, W. Australia, 1969), Phytophthora cryptogea Pethybr. \& Lafferty (APCC $4601 \mathrm{f}$ from GCRI 72/5, $\mathrm{A}_{2}$, ?origin, prior to 1980), Phytophthora gonapodyides (Petersen) Buisman (APCC 4501a, N.W. England, 1965 $\dagger$ ), Phytophthora palmivora (Butler) Butler (APCC 4607a, from IMI 131374 from ATCC 15406, ?origin, prior to 1968), Phytophthora undulata (Petersen) Dick (APCC 4701 a* $\equiv$ APCC 4414a to IMI 308278, BC, Canada, 1969†).

Cultures used by Belkhiri \& Dick (1988) are indicated by *; cultures isolated by or under the direction of M.W. Dick are indicated by + . With the possible exceptions of the Japanese isolates $P$. aphanidermatum and $P$. paddicum, the cultures came from populations which have, to our best knowledge, never been exposed to hymexazol or metalaxyl, and therefore have not been exposed to prior selection. We can thus compare inter- rather than intra-specific variation.

Media and fungicides. Hymexazol (purity $93.4 \%$ ) was synthesized at the Agricultural Chemicals Research Laboratories, Sankyo Co., Shiga, Japan. Metalaxyl, as Ridomil 25WP (sample ref. T2942) was supplied by Ciba-Geigy Agrochemicals, Cambridge, UK. Hymexazol is readily soluble in water $\left(8.5 \%, \mathrm{w} / \mathrm{v}\right.$, at $\left.25^{\circ} \mathrm{C}\right)$ and was dissolved in a corn meal agar (CMA) medium held at about $50^{\circ} \mathrm{C}$ to obtain the given concentration. Metalaxyl was incorporated into CMA similarly.

Culture system. Linear growth rate in agar was measured using Ryan tubes (Ryan et al., 1943). Preliminary tests indicated that the magnitude of the inoculation shock was variable betwen species but in all cases in which measurable growth occurred, growth rates stabilized within several hours of inoculation and remained constant for at least $15 \mathrm{~d}$ thereafter. We chose not to complicate the already complex analysis by incorporating the lag-phase following inoculation in our model. Therefore, the base measurement for linear extension was made $3 \mathrm{~d}$ after inoculation and the linear rate was calculated from further measurements made after 5,7 and $9 \mathrm{~d}$. Failures of any control culture or culture in which growth was anticipated necessitated a repeat run of the entire block of 25 tubes ( 5 species $\times 5$ treatments).

Preliminary tests also showed that the diameter of the Ryan tube was not critical and so tubes of 15 or $18 \mathrm{~mm}$ diameter and $300 \mathrm{~mm}$ length were used. The volume of agar added was $15 \mathrm{ml}$ ( $15 \mathrm{~mm}$ diam. tube) or $20 \mathrm{ml}(18 \mathrm{~mm}$ diam. tube). Each tube was inoculated with a $4 \mathrm{~mm}$ diam. mycelial agar disc taken from the mycelial margin of a Petri-dish culture in the linear phase of growth on CMA, except for Verrucalvus flavofaciens and Pachymetra chaunorhiza. In the case of these two species, it was necessary to use, as inoculum, a hemp seed which had been precolonized and incubated in glass distilled water (Dick $e t$ al., 1984, 1989). All pilot and Ryan tube cultures were incubated at $20^{\circ} \mathrm{C}$.

Fungicide concentrations. The hymexazol concentrations used were 0 (the contemporary control for each species in each lattice block), 1, 4, 40 and 100 p.p.m. Metalaxyl concentrations of $0,0.5,2,20$ and 600 p.p.m. were used.

Statistical methods. The data consist of measurements of percentage inhibition of extension, $y_{\mathrm{ijk}}$, for replicate $k(k=1, \ldots 6)$ of concentration $j(j=1,4,40,100$ p.p.m.) on species $i(i=1, \ldots 25)$.

Analysis of variance showed that any block-to-block differences had been removed by recording extension relative to the contemporaneous control. Means over replicates did not, therefore, need adjusting for block differences.
Groupings of the species were first investigated by cluster analysis. The mean percentage inhibitions, $y_{\mathrm{ij}}$, of each concentration were taken as four variables representing each species. Euclidean distance, using variables scaled by their range, and average linkage were used to form clusters of species (Payne et al., 1987).

The response of percentage inhibition to concentration was modelled using dose response curves of the form

$$
y=100-a \exp (-b x)
$$

where $x$ is the concentration and $a$ and $b$ are constants. This curve was found not to be flexible enough for all species and an additional parameter $c$ was added to give

$$
y=100-a \exp \left(-b x^{c}\right)
$$

The parameter $c$ was chosen to make a plot of $z=\log (100-y)$ against $x^{\mathrm{c}}$ linear. Parameters $a$ and $b$ were then estimated by regression of $z$ on $x^{c}$. The parameters $a, b$ and $c$ are not easy to interpret, so similarities and differences in dose response for the 25 species were displayed by choosing four distinguishing characteristics of the curves that could be calculated from $a, b$ and $c$ and then be plotted. The four characteristics were: $(a)$ the concentration needed to give an inhibition of $90 \%\left(\mathrm{LD}_{90}\right)$; (b) the slope of the dose response curve at $\mathrm{LD}_{90}\left(\mathrm{SLD}_{90}\right) ;(c)$ the inhibition at a concentration of 4 p.p.m. $\left(Y_{4}\right)$; and $(d)$ the slope of the curve at $\mathrm{Y}_{4}\left(\mathrm{SY}_{4}\right)$.

A three-dimensional scatter plot of $\mathrm{LD}_{90}, \mathrm{Y}_{4}$ and $\mathrm{SLD}_{90}$, with the symbol size determined by $\mathrm{SY}_{4}$, was generated by computer. In order to obtain a clearly displayed plot the variables had to be scaled, rendering numerical labels on the axes not easily interpreted. Actual values of the variables can be seen in the response curves.

\section{Results and Discussion}

The first criterion for this study was to use as diverse a range of Oomycetes as possible. The maximum number that could be handled in the balanced lattice design (Cochran \& Cox, 1957, and see below) was 25. Intraspecific variation was deliberately excluded on the grounds that it was considered unlikely that a substantial proportion of the 25 species isolates would be abnormal and that the experimental design for the demonstration of intra-specific norms and differences would be different from, and incompatible with, the fungicide levels used for inter-specific differences. The second criterion was the choice of a growth system. Linear extension rate in agar was chosen in preference to broth culture because several of the taxa which were likely to be of critical importance do not grow well in liquid media. The third criterion was to attempt to select fungicide concentrations which would span a sufficiently wide range for all test species and allow inhibition response curves to be constructed. The range of concentrations therefore had to be wider than would be used in conventional resistance studies, or for intra-specific comparisons. Four concentration levels were necessary to characterize all 25 species (Fig. $1 a-e$ ).

As in the previous study using this incomplete lattice block design (Hardman \& Dick, 1989), the ANOVAR test revealed no significant variation between the replicates made on different occasions. 

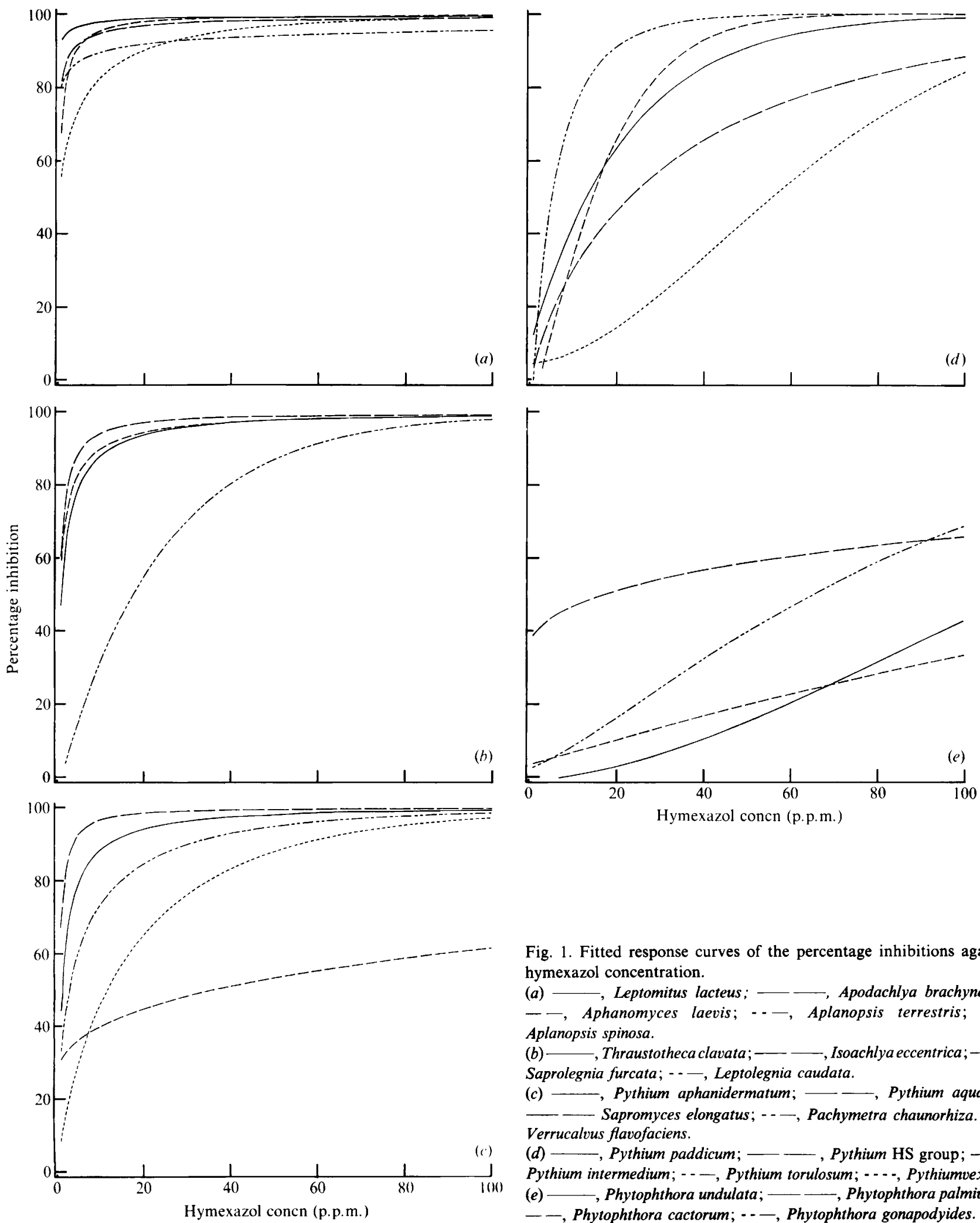

Fig. 1. Fitted response curves of the percentage inhibitions against hymexazol concentration.

(a) —_, Leptomitus lacteus; ___ _ Apodachlya brachynema; -- Aphanomyces laevis; - - , Aplanopsis terrestris; - Aplanopsis spinosa.

(b) - , Thraustotheca clavata;-_——, Isoachlya eccentrica;-—-, Saprolegnia furcata; - - , Leptolegnia caudata.

(c) - - Pythium aphanidermatum; ——, Pythium aquatile; - Sapromyces elongatus; -- -, Pachymetra chaunorhiza. - --, Verrucalvus flavofaciens.

(d) - — , Pythium paddicum; ———, Pythium HS group; - Pythium intermedium; - - -, Pythium torulosum; -..-, Pythiumvexans. (e) - , Phytophthora undulata; - — Phytophthora palmivora; - , Phytophthora cactorum; -.-, Phytophthora gonapodyides. 


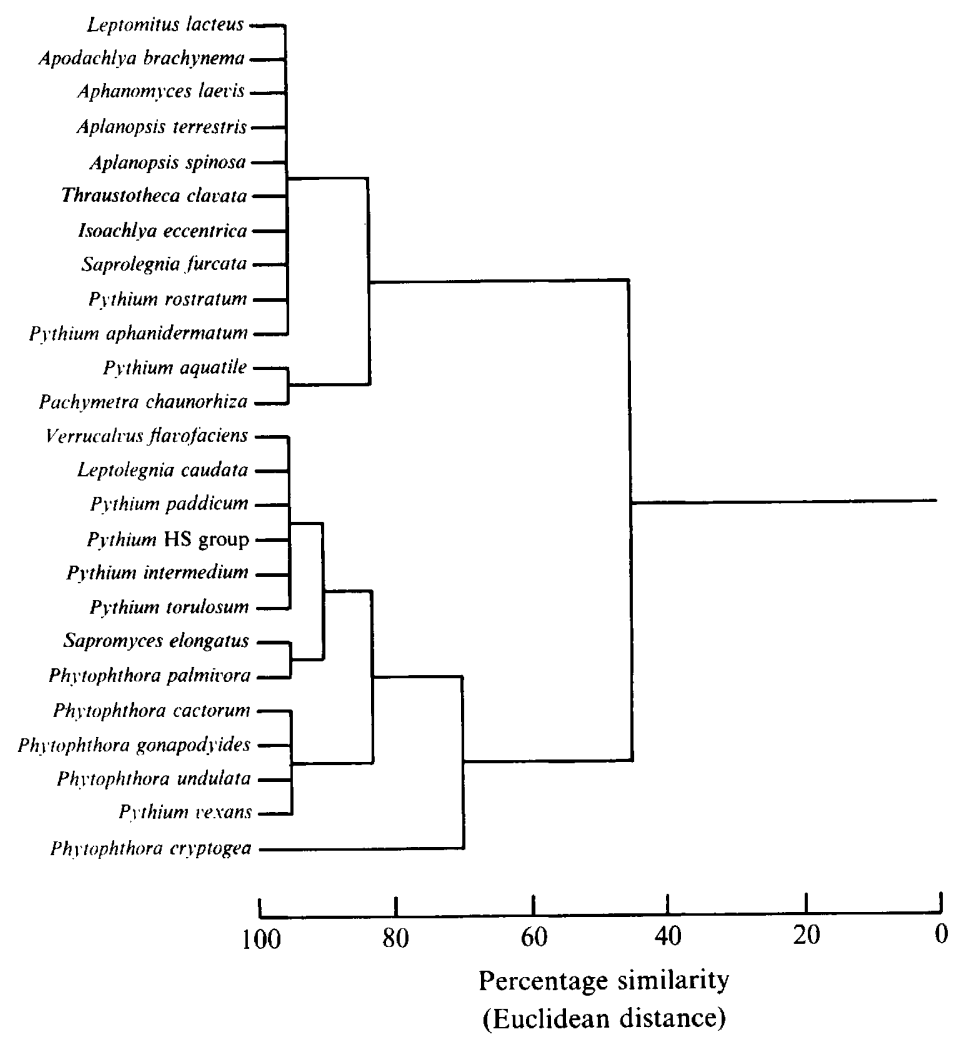

Fig. 2. Phenogram derived from cluster analysis of the percentage inhibition by hymexazol of growth of the 25 species.

Individual species vary in their actual linear extension rates and it is an important part of our experimental design that comparisons are made as percentages of the control rate, in effect normalizing the data. Extension rates of species on CMA without hymexazol (the controls) varied from $0.72 \mathrm{~mm} \mathrm{~d}^{-1}$ for Sapromyces elongatus to $22.2 \mathrm{~mm} \mathrm{~d}^{-1}$ for Pythium torulosum.

Fig. 2 shows the phenogram derived from the cluster analysis of the percentage inhibitions of 25 species (raw data). All species were contained within two large subgroups at the level of $45 \%$ similarity. The first group included all species of the Saprolegniales with the exception of Leptolegnia caudata, three Pythium spp. ( $P$. rostratum, $P$. aphanidermatum and $P$. aquatile) and Pachymetra chaunorhiza. The second large subgroup was divided into three small subgroups at the level of $90 \%$ similarity with the exception of Phytophthora cryptogea which was diverted at the $70 \%$ similarity level. The first small subgroup included the remaining Pythium species except $P$. vexans, plus Verrucalvus flavofaciens and Leptolegnia caudata. The second small subgroup included Sapromyces elongatus and Phytophthora palmivora. The third small subgroup included the remaining Phytophthora species and Pythium vexans. Fitting of the response model (1) to percentage inhibitions was successful for all species except Pythium rostratum and Phytophthora cryptogea. The data for Pythium rostratum (95.5, 100.0, 100.0 and $100.0 \%)$ and for Phytophthora cryptogea $(-2.5$, $-4.0,-13.2$ and $-2.9 \%$ ) at $1,4,40$ and 100 p.p.m. respectively) were not amenable for fitting to the model (1). The multivariate plot (Fig. 3) shows the discreteness of the taxonomic groups, with a few notable exceptions. Most sensitive to the fungicide were the taxa of the Leptomitales, followed by the taxa of the Saprolegniales. Species of Phytophthora were the least sensitive. Phytophthora palmivora was separated somewhat from the other species of Phytophthora, but was close to Sapromyces elongatus. Occupying an intermediate position were Verrucalvus flavofaciens and Pachymetra chaunorhiza (Sclerosporales). The responses of Pythium were notably diverse ranging from Pythium aquatile which was shown close to Apodachlya brachynema and Pythium vexans which was close to Phytophthora.

From a comparison of the cluster analysis (Fig. 2) with the multivariate plot (Fig. 3) there can be little dispute that hymexazol response follows accepted taxonomic groupings. However, the multivariate plot provides considerable clarification of some apparent discrepancies such as the separation of Verrucalvus and Pachymetra in the cluster analysis. The response of Leptolegnia 


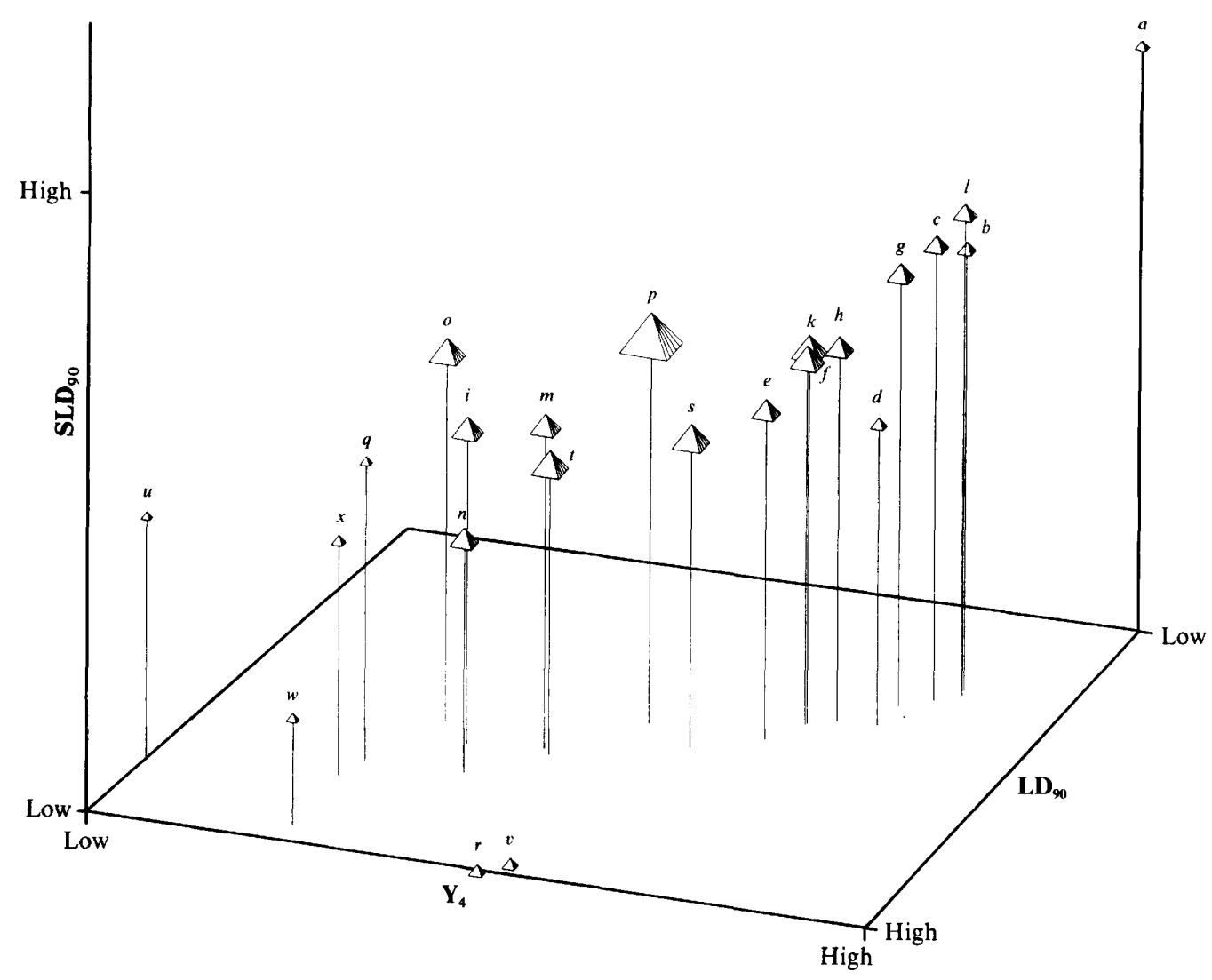

Fig. 3. Multivariate plot of responses of Oomycetes against hymexazol. The variables used are concentration $\left(\mathrm{LD}_{90}\right)$ and slope at $90 \%$ inhibition and percentage inhibition and slope at 4 p.p.m. which are derived from the fitted models. Sizes of pyramids indicate slopes at 4 p.p.m. See text for explanation of axes designations. (a) Leptomitus lacteus; (b) Apodachlya brachynema; $(c)$ Aphanomyces laevis; $(d)$ Aplanopsis terrestris; (e) Aplanopsis spinosa; ( $)$ Thraustotheca clavata; $(g)$ Isoachlya eccentrica; (h) Saprolegnia furcata; $(i)$ Leptolegnia caudata; $(k)$ Pythium aphanidermatum; (l) Pythium aquatile; $(m)$ Pythium paddicum; $(n)$ Pythium HS group; $(o)$ Pythium intermedium; $(p)$ Pythium torulosum; $(q)$ Pythium vexans; $(r)$ Sapromyces elongatus; $(s)$ Pachymetra chaunorhiza; $(t)$ Verrucalvus flavofaciens; $(u)$ Phytophthora undulata; (v) Phytophthora palmivora; (w) Phytophthora cactorum; $(x)$ Phytophthora gonapodyides.

caudata was unlike the rest of the Saprolegniales, and showed a closer relationship to the Sclerosporales. There are morphological grounds for regarding this species of Leptolegnia as possibly having a basal position within the Saprolegniomycetidae. If these three taxa are relatively close to an ancestral condition for the characters investigated here, then the two-dimensional split of the cluster analysis (Fig. 2) between Verrucalvus and Pachymetra can be explained; the multivariate analysis diagram (Fig. 3) imposes no artificial constraint.

Although the diversity of Pythium responses was remarkable, the separation of most of the Pythium species from species of Phytophthora was obvious. The response of Pythium vexans was unlike the rest of the Pythium species but very close to Phytophthora, and it is noteworthy that the ribosomal DNA (rDNA) of this species failed to show the typical character for the genus Pythium (Belkhiri \& Dick, 1988). This species is distinctive within Pythium because of its broadly apical attachment of the antheridia. Further morphological and biochemical studies involving many isolates, worldwide, will be needed to clarify the generic status of Pythium vexans. This situation is different from that of Phytophthora undulata, recently transferred from Pythium to Phytophthora on the grounds of rDNA characteristics (Belkhiri \& Dick, 1988) and the re-examination of zoosporogenesis (Dick, 1989). The latter unequivocally confirms the transfer which was stimulated by the biophysical data.

The responses of Pythium showed great diversity ranging from $P$. rostratum, which was so sensitive that data could not be described by the model, to $P$. vexans. The continuum displayed for Pythium in Fig. 3 does not correlate with other known features of these taxa, such as sporangial form. However, we should draw attention to an interesting coincidence, in that the three close pairs on Fig. 3, viz. $P$. aquatile and $P$. aphanidermatum, $P$. torulosum and $P$. paddicum, and Pythium HS group and $P$. 
intermedium, were also paired on the basis of DNA profiles (Belkhiri \& Dick, 1988). The three pairs had different relative sequences in the two studies.

These results need to be considered in relation to the biology of these species. Among some representative parameters of fungal growth rate, such as dry weight, hyphal extension rate (Trinci, 1974), radial growth rate of colonies etc., linear extension rate was used in this study as one means for comparison of diverse species. Unpublished data on a few Pythium species indicate that different parameters of growth assessment (e.g. dry weight) followed the same general trends revealed by linear extension rate.

Actual growth rates differ between species; thus, the response curves were derived from percentage inhibitions relative to linear growth rates of the controls. These percentage inhibitions must be related to levels of tolerance and speed of reaction to the fungicide. Most of the Saprolegniales showed a rapid response and high levels of sensitivity. On the other hand, responses of Phytophthora were delayed and showed lesser sensitivities. Nakanishi \& Sisler (1983) reported that uptake of hymexazol by Pythium aphanidermatum from an ambient solution was small and reached a maximum within $2 \mathrm{~h}$; uptake by Phytophthora drechsleri was larger than that by Pythium aphanidermatum and increased continuously during $6 \mathrm{~h}$ of incubation. These phenomena may be related to the sensitivity of the receptor (target) sites of the fungicide and/or their accessibility.

A parallel but less rigorously analysed study, using the same isolates in the same lattice, but with different concentrations of metalaxyl produced a coarse arbitrary categorization (Table 1).

It is worth noting some similarities and differences of the metalaxyl data with the hymexazol study. The Saprolegniaceae and Leptomitaceae showed the least sensitivity to metalaxyl and Phytophthora the greatest sensitivity. This is in direct contrast to hymexazol sensitivities. Pythium species again showed a range of responses. Note that Pythium vexans is again grouped with Phytophthora. However, Pythium rostratum was highly sensitive to both fungicides. Sapromyces elongatus was comparable to the Saprolegniaceae with respect to metalaxyl but to Phytophthora with respect to hymexazol sensitivity. Within Pythium and Phytophthora different rankings were apparent for the two fungicides, with metalaxyl inducing less inhibition in most of the socalled 'aquatic' species (but compare Phytophthora gonapodyides and Phytophthora undulata).

\section{General discussion}

Further development from this analysis of the diversity of responses to fungicides must first be to test a sufficient
Table 1. Species ranking in approximately ascending order of sensitivity to metalaxyl

Values are percentage inhibition by metalaxyl of linear growth rate measured in Ryan tubes (means of measurements made at three consecutive $48 \mathrm{~h}$ periods, 5, 7 and $9 \mathrm{~d}$ after inoculation). Arbitrary 'cut-off' points are indicated. Values are rounded to the nearest $1 \%$.

\begin{tabular}{|c|c|c|c|c|}
\hline $\begin{array}{l}\text { Metalaxyl } \\
\text { concn (p.p.m.) }\end{array}$ & 0.5 & 2 & 20 & 600 \\
\hline Cut-off point & $<15$ & $<15^{*}$ & $<20$ & \\
\hline Sapromyces elongatus & -16 & -12 & -19 & 48 \\
\hline Pachymetra chaunorhiza & -45 & 4 & -5 & 93 \\
\hline Thraustotheca clavata & -32 & 5 & -1 & 66 \\
\hline Isoachlya eccentrica & 2 & -1 & 4 & 42 \\
\hline Aplanopsis spinosa & -10 & 0 & 20 & 73 \\
\hline Aplanopsis terrestris & 1 & 4 & 5 & 36 \\
\hline Aphanomyces laevis & 4 & 4 & 4 & 61 \\
\hline Verrucalvus flavofaciens & 3 & 9 & 5 & 62 \\
\hline Saprolegnia furcata & 13 & 14 & 15 & 58 \\
\hline Apodachlya brachynema & 8 & 19 & 15 & 61 \\
\hline Cut-off point & & $15-30$ & $>65$ & \\
\hline Pythium paddicum & -1 & 22 & 97 & 100 \\
\hline Pythium torulosum & 8 & 26 & 90 & 100 \\
\hline Leptolegnia caudata & 13 & 18 & 100 & 100 \\
\hline Cut-off point ... & $<40^{*}$ & $55-80^{*}$ & & \\
\hline Phytophthora gonapodyides & 31 & 70 & 69 & 94 \\
\hline Pythium aquatile & 28 & 60 & 83 & 99 \\
\hline Pythium aphanidermatum & 38 & 77 & 99 & 100 \\
\hline Pythium intermedium & 36 & 81 & 100 & 100 \\
\hline Pythium HS group & 54 & 56 & 98 & 99 \\
\hline Cut-off point $\ldots$ & $>50^{\dagger}$ & $>85^{*}$ & & \\
\hline Phytophthora palmivora & 27 & 92 & 99 & 100 \\
\hline Phytophthora cactorum & 28 & 94 & 100 & 100 \\
\hline Phytophthora undulata & 51 & 99 & 100 & 100 \\
\hline Pythium vexans & 67 & 84 & 98 & 100 \\
\hline Pythium rostratum & 81 & 94 & 99 & 100 \\
\hline Phytophthora cryptogea & 87 & 95 & 100 & 100 \\
\hline
\end{tabular}

number of different isolates of the same species to enable statistical analysis of geographic, habitat and intrapopulation variation. Ranges of concentrations of fungicides must be selected to give maximum information on the shape of the inhibition curve leading to the $\mathrm{LD}_{90}$ point.

Secondly, the life-form responses to fungicide concentrations should be assessed in relation to the different life-histories of congeneric species (Ali-Shtayeh et al., 1986; Hardman et al., 1989; Hardman \& Dick, 1989; Pearson et al., 1990; Dick, 1990).

A much more fundamental consideration concerns the barriers to fungicidal action that result in the different responses of congeneric species. Selective fungicides, e.g. metalaxyl, benomyl, are either known or suspected to act on vital synthetic processes (Davidse et al., 1983; Davidse, 1986). In both of these examples resistant strains have soon become noted, indicating that a small change in the amino acid sequence (i.e. a single gene 
mutation) of the target site can affect fungicidal activity. It has still to be established whether differences in shapes of the inhibition curves between resistant and susceptible strains of one species span the range of inter-specific differences reported here.

If the mode of action is fundamental to somatic growth, any differences in the degree of sensitivity within phylogenetically related organisms must be due to the efficiencies of any hurdles barring access to the target site. Various kinds of hurdles can be envisaged, relating either to degrees of immobilization due to binding, inactivation or degradation of the active parts of the fungicide molecule, or to the propensities for adaptive change in the metabolism of the fungus exposed to the fungicide. Immobilization is known for higher plants (Jacob \& Neumann, 1987). Differences between sensitive and resistant strains of a fungus may also be due to the extent of degradation of the fungicide (Vesugi \& Sisler, 1978). Many enzymes that will degrade a fungicide are group-specific, thus a change in the stereochemistry or charge of the non-active part may affect biodegradability. Phosphorylation, $\mathrm{Ca}^{2+}$-calmodulin interaction and the extent of amino acid cross-linkages (particularly S-S bonds) of the target site could also affect the sensitivity of the fungus to the fungicide. The amino acid composition of the protein of the target site will be relevant to the shape of the target site, and will thus relate to sensitivity to fungicide on the one hand, and to the DNA code (i.e. phylogeny) for the protein on the other hand.

To date, biochemical studies on plasma membrane composition and construction have not considered the subtle differences between related oomycetes that may occur because of life-form and life-history differences, and which may be responsible for the differences reported here.

The kinds of barriers, or defences against fungicidal access, from the outside inwards, can be listed as follows:

I. Detoxification at a distance by means of extracellular enzymes.

II. Adsorption by mucilages (carbohydrate or protein) secreted through the cell wall and deposited on the surface of the cell wall. Differential secretion of mucilages has been described: for example the oogonial mucilage of Aplanopsis (Dick, 1969).

III. The adsorptive properties and enzymic attributes of the cell wall itself. Comparative differences in the wall chemistry of Oomycetes have been described by VaziriTehrani \& Dick $(1980 a, b)$.

IV. The composition of the plasma membrane (percentages and kinds of phospholipids, proteins and sterol derivatives) which may prevent entry.

V. Protective mechanisms may exist within the cytoplasm, taking the forms of (a) detoxifying enzyme systems, such as peroxidases, $(b)$ the ability to switch to alternative metabolic pathways via adaptive enzyme systems, $(c)$ the frequency of lipid-rich vacuolar systems (lysosomes or vacuolar 'rubbish bins') through which detoxification may be achieved by incorporation within the vesicular system. Little is publicly known about the comparative aspects of catabolism, although agrochemical companies may have relevant information from confidential residue analyses.

VI. The rates of production and natural turnover of the target site (i.e. numbers of potentially vulnerable sites at any moment in time). Dynamic metabolic studies may provide some data here.

This study indicates those organisms that are particularly favourable for further study of the sites of interaction, either because of sensitivity or resistance to the fungicide, or because of particular vulnerability at particular stages of the life-history.

It is important that fungicidal mixtures and applications should maximize crop protection and simultaneously minimize damage to related species of fungi in the community, thereby causing least disruption to the environment. Damage to the balance of the microbial community has seldom been emphasized in fungicidal testing.

The work with metalaxyl was done by Mr S. R. Langrell as an undergraduate honours project. The full lattice was not completed.

\section{References}

Ali-Shtayeh, M. S., Lim-Ho, C. L. \& Dick, M. W. (1986). The phenology of Pythium (Peronosporomycetidae) in soil. Journal of Ecology 74, 823-840.

BELkHIRI, A. \& Dick, M. W. (1988). Comparative studies on the DNA of Pythium species and some possibly related taxa. Journal of General Microbiology 134, 2673-2683.

Cochran, W. G. \& Cox, C. W. (1957). Experimental Designs, 2nd edn. New York: John Wiley.

DAVIDSE, L. C. (1986). Benzimidazole fungicides : mechanism of action and biological impact. Annual Review of Phytopathology 24, 43-65.

Davidse, L. C., Hofman, A. E. \& Velthuis, G. C. M. (1983). Specific interference of metalaxyl with endogenous RNA polymerase activity in isolated nuclei from Phytophthora megasperma f. sp. medicaginis. Experimental Mycology 7, 344-361.

Dick, M. W. (1969). Morphology and taxonomy of the Oomycetes, with special reference to Saprolegniaceae, Leptomitaceae and Pythiaceae. I. Sexual reproduction. New Phytologist 68, 751-775.

Dick, M. W. (1989). Phytophthora undulata comb. nov. Mycotaxon 35, 449-453.

Dick, M. W. (1990). Patterns of phenology in populations of zoosporic fungi. In The Fungal Community: Its Organization and Role in the Ecosystem, 2nd edn. Edited by G. C. Carroll and D. T. Wicklow. New York: Marcel Dekker (in the Press).

Dick, M. W., Wong, P. T. W. \& Clark, G. (1984). The identity of the oomycete causing 'Kikuyu Yellows', with a reclassification of the downy mildews. Botanical Journal of the Linnean Society 89, 171-197.

Dick, M. W., Croft, B. J., Magarey, R. C., De CoCk, A. W. A. M. \& Clark, G. (1989). A new genus of the Verruculvaceae (Oomycetes). Botanical Journal of the Linnean Society 99, 97-113. 
Hardman, J. M. \& Dick, M. W. (1989). Comparative resilience to dilution plate procedures shown by zoospore cysts of twenty Pythium species and five Phytophthora species. Mycological Research 93, 383385.

Hardman, J. M., Pike, D. J. \& Dick, M. W. (1989). Short-term retrievability of Pythium propagules in simulated soil environments. Mycological Research 93, 199-207.

Ho, H. H. (1987). Effect of hymexazol on growth and reproduction of low temperature Phytophthora species. Mycopathologia 98, 17-20.

Jacob, F, \& Neumann, ST. (1987). Principles of uptake and systemic transport of fungicides within the plant. In Modern Selective Fungicides, pp. 13-30. Edited by H. Lyr. New York: Longman.

Masago, H., Yoshikawa, M., Fukuda, M. \& NaKanishi, N. (1977). Selective inhibition of Pythium spp. on a medium for direct isolation of Phytophthora spp. from soil and plants. Phytopathology 67, 425428.

NAKANISHI, T. \& SisLer, H. D. (1983). Mode of action of hymexazol in Pythium aphanidermatum. Journal of Pesticide Science 8, 173-181.

PAYNe, R. W. AND Others (1987). GENSTAT 5 Reference Manual. Oxford: Oxford University Press.

Pearson, J., Pike, D. J. \& Dick, M. W. (1990). A model for short-term fluctuations of Pythium propagules in soil. Mycological Research (in the Press).
Ryan, F. J., Beadle, G. W. \& Tatum, E. L. (1943). The tube method of measuring the growth rate of Neurospora. American Journal of Botany 30, 784-799.

TaKaHI, Y., Nakanishi, T., Tomita, K. \& Kaminura, S. (1974). Effect of 3-hydroxy isoxazoles as soil fungicides in relation to their chemical structures. Annals of the Phytopathological Society of Japan 40, 354-361.

TRINCI, A. P. J. (1974). A study of the kinetics of hyphal extension and branch initiation of fungal mycelia. Journal of General Microbiology 81, 225-236.

Vesugi, Y. \& Sisler, H. R. (1978). Metabolism of a phosphoramidate by Pyricularia oryzae in relation to tolerance and synergism by a phosphorothiolate and isoprothiolane. Pesticide Biochemical Physio$\log y$ 9, 247-254.

VAZIRI-TEhrani, B. \& Dick, M. W. (1980a). Taxonomic significance of variations between ratios of cell wall amino acids in fungi, with special reference to Oomycetes. Transactions of the British Mycological Society 74, 231-238.

VAZIRI-TEHRANI, B. \& Dick, M. W. (1980 b). Neutral and amino sugars from the cell walls of Oomycetes. Biochemical Systematics and Ecology 8, 105-108. 